Article

\title{
Mobility Acceptance Factors of an Automated Shuttle Bus Last-Mile Service
}

\author{
Ralf-Martin Soe ${ }^{1, * \mathbb{D}}$ and Jaanus Müür ${ }^{2}(\mathbb{D}$ \\ 1 FinEst Twins Smart City Center of Excellence, Tallinn University of Technology, 19086 Tallinn, Estonia \\ 2 Ragnar Nurkse Department of Innovation and Governance, Tallinn University of Technology, \\ 12618 Tallinn, Estonia; jaanus.muur@taltech.ee \\ * Correspondence: ralf-martin.soe@taltech.ee
}

Received: 21 May 2020; Accepted: 3 July 2020; Published: 7 July 2020

check for updates

\begin{abstract}
The main interest of this paper is to analyze the mobility acceptance factors of an automated shuttle bus last-mile service. There is limited research on the passengers' perception of security and safety of automated mobility, whereas prior research is mostly based on surveys interested in attitudes towards self-driving vehicles, without being linked to the experience. We, on the other hand, are interested in passengers' feeling of security and safety, after taking a ride with an automated shuttle in an open urban environment. For studying this, we conducted an automated shuttle bus last-mile pilot during a four-month period in the city of Tallinn in late 2019. The method is a case study focusing on one city with several tools for data collection applied (surveys, interviews, document analysis). The pilot, open and free for everybody, attracted approximately 4000 passengers, out of which $4 \%$ responded to the online feedback survey. For studying the operational capacity, we had a panel interview with operators of the shuttle service, in addition to analyzing daily operational $\log$ files. The results indicate that passengers' perceived feeling of security and safety onboard was remarkably high, after taking a ride (and lower without a ride, in a different control group). The bus was operated only if operational capacity was secured, thus having significant downtime in service due to environment, technology and traffic-related factors.
\end{abstract}

Keywords: automated mobility; sustainable transportation; urban mobility; last-mile; passenger's safety; passenger's security; operational capacity

\section{Introduction}

In the context of urbanization, cities face challenges related to the growing number of cars on the streets, which, in turn, causes traffic congestions and increases the overall emissions. Thus, cities are showing increasing interest towards shared, automated and electric mobility. However, the adoption of automated vehicles (AVs) can be challenging because of reasons related to passenger safety, passenger security and operational capacity. Passenger safety is understood here as the passengers' subjective feeling of traffic safety onboard an automated bus. Passenger security is understood as the passengers' subjective feeling of security onboard an automated bus. Operational capacity refers to the quality of service of an automated bus influenced by the factors of environment, traffic and technology. Although there are several studies measuring the attitudes towards transference from manual to automated driving based on non-experimental surveys [1-5], there are very limited perception studies that are based on the actual experiment of automated trials. Therefore, one of our key interests is to investigate passengers' perceived risk aversion regarding security and safety of automated urban mobility. The second key interest of this study is to map out the main factors which can affect the operations of an automated shuttle bus and how they were addressed. The occurrence of different issues and how they were addressed can also influence the passenger experience, including their 
perceived safety and security. Thus, the overall contribution of this paper is to address the differences between perceived safety and security concerns versus technological challenges of integrating such a last-mile service with urban mobility.

This paper is based on a last-mile shared automated mobility pilot that was conducted on the open urban roads in Tallinn, the capital of Estonia, in the second part of 2019. The pilot was open and free for all interested passengers. The passengers were also offered the possibility to fill in an online survey which was available in Estonian and English. The case study results were triangulated with panel interviews of the Tallinn pilot shuttle bus operators in early 2020, daily operational log files and with a control group of 55 students that answered the survey without actual automated driving experience. Section 2 provides an overview of literature which focuses on AVs and introduces the research gap. Section 3 describes the used methodology and introduces the automated shuttle bus pilot in Tallinn. Section 4 brings out the main results. Section 5 summarizes the paper.

\section{Literature Review and the Research Gap}

This section starts with an overview of the possible impact of the technology of AVs. The reason for such an overview is to picture the magnitude of change that could happen when AVs become widely adopted. It also helps to better understand the importance of investigating user acceptance and how the passengers perceive safety and security in relation to AVs. It is followed by the overview of research which focuses on investigating user acceptability and the research gap that this paper investigates.

\subsection{The Impact of $A V s$}

During the last seven years (2013-2020), several academic publications and reports have been published that focus on the impact of autonomous vehicles. An early study by Fagnant and Kockelman [6] estimated that shared autonomous vehicles (SAVs) could diminish the vehicle fleet size by ten times. In the later study of Fagnant and Kockelman [7] which was based on a simulation of Austin, Texas, they estimated that one SAV could replace 10.77-11.53 cars, depending on how many trips are shared between passengers. Similarly, an OECD [8] study found that the combination of TaxiBots together with high-capacity public transportation would remove 9 out of 10 cars in mid-sized cities in the case of the city of Lisbon. These studies have also analyzed the impact on emissions and total travel kilometers. In the EU, approximately one-fifth of greenhouse gas emissions is produced by road transport (https://www.eea.europa.eu/data-and-maps/indicators/transport-emissions-of-greenhousegases/transport-emissions-of-greenhouse-gases-12). Reduction of emissions due to automation has been estimated by several studies [6,9] but it will also depend on what kind of technology will be used [8]. Studies have also estimated different impacts on the total amount of travel kilometers. As Martinez and Viegas [9] argue, the actual impact depends on how the technology will be deployed. In reality, it will depend on which transport modes are used and how fast they will be automated, as well as what the combination of different transport modes will be and how many rides are shared [9].

Several publications have analyzed the impact of AVs and SAVs on other aspects of mobility. It has been argued that autonomous vehicles will provide greater access to mobility for population groups who currently are disadvantaged such as the elderly, youth and people without a driver's license, as well as change people's mobility patterns $[7,10,11]$.

Land use will heavily be impacted by autonomous transportation. It has been argued that the introduction of autonomous vehicles could bring a second wave of suburbanization [12,13]. As Heinrich [13] argues, autonomous driving can compensate for longer travel distances as the passenger(s) can be engaged with productive activities while commuting. This could be a tempting choice by many as the land prices in suburban areas are much cheaper compared to the urban centers [12]. In the cities, the districts could be organized around transport hubs in which public transportation is provided by autonomous vehicles, which, in turn, will reduce the need for parking spaces [13]. A study conducted by Zhang and Guhathakurta [14] estimates that with only $5 \%$ of the trips served with SAVs, the parking land use in Atlanta could be reduced by $4.5 \%$. A similar reduction 
was found with the case of Lisbon, where a 100\% shared self-driving taxibot fleet could reduce parking spaces by more than $90 \%$ [8].

Clements and Kockelman [15] have estimated that when connected AVs will capture the majority of the automotive market, their impact on the whole US economy would be 1.2 trillion dollars annually, as such a development would affect numerous industries such as insurance, electronics, freight movement, the car industry and others by destroying the current business models and creating new ones. The car industry will especially be under heavy pressure if SAVs will dominate over private AVs, as the sale of cars to private individuals, which is the current main business for car manufacturers, will drop significantly. On the other hand, the increased mileage and active service hours per SAV will shorten the life cycle of the vehicles, which, in turn, creates additional demand $[8,9]$. The deployment of AVs and SAVs also require large investments in infrastructure which has an impact on the economy. This includes investments in charging stations and the electric grid [16]. Further investments are required in sensor technology, software, batteries, and electric motors [16]. AVs could also potentially provide efficiency gains. Ongel et al. [17] predict that adapting autonomous electric vehicles in Singapore's public transport system would reduce total cost of ownership per passenger kilometer around $60 \%$ compared to the regular buses. We could also expect a decrease in real estate development costs and more affordable urban housing as SAVs would eliminate the need to invest in building garages for private cars [16]. Changes in land use and new service opportunities provided by autonomous driving will also impact tourism. Cohen and Hopkins [18] bring out several possible changes and challenges that AVs might bring in tourism such as pre-planned sightseeing routes, targeted advertising in AVs and SAVs, loss of employment (couch and taxi drivers), decreased encounters between locals and tourists, etc. Pre-planned routes can also decrease market competition when AVs and SAVs will take people only to businesses that pay the fleet operators [18].

\subsection{User Acceptance and Perception of Security and Safety}

As the wide adoption of private $\mathrm{AVs}$, SAVs and autonomous public transport would certainly have an impact on the economy and society at large, user acceptance and passengers' safety and security perception become important topics to investigate. Several studies have been conducted to evaluate user acceptability and willingness to purchase this technology. A cross-national study with 5000 respondents from 109 countries conducted by Kyriakidis et al. [4] found out that while most of the people find manual driving most enjoyable, a large proportion favored fully autonomous driving. Prior experience seems to be the key reason. They found that frequent drivers are more willing to pay for autonomous features [4]. In addition, people with prior experience with adaptive cruise control are more willing to pay for AVs, more comfortable with driving without a steering wheel and more comfortable with data transmission [4]. Similar results were given by the study of Zmud et al. which analyzed the answers of a survey with 556 respondents [5]. They concluded that people whose current vehicle has highly automated features showed higher intent to use self-driving vehicles. The study conducted by Pakusch and Bossauer [19] focuses on fully automated public transport systems. The results of their study are in line with previously mentioned studies-people who have prior experience with automated transportation such as automated trams, trains, and metro are more willing to use autonomous transport than people without such experience. In addition, the participants of their study preferred autonomous rail-bound transportation over autonomous private cars, buses, taxis and carsharing.

The fact that a person has had prior experience with an SAV and has shown willingness to use it in the future does not mean that the same person is also willing to use a privately-owned $\mathrm{AV}$ or vice versa. However, the aforementioned studies do show that prior experience with the technology can increase the willingness to use the technology in the future.

Safety is one of the key aspects in the adoption of any kind of autonomous vehicle. It has been argued that the technology has the potential to significantly reduce the number of traffic accidents that are caused by driver error [20]. Although the potential is there, concerns over the safety of the technology must be acknowledged. The study by Kyriakidis et al. [4] found safety as one of the biggest 
concerns related to automated driving. According to the survey conducted by Zmud et al. [5], the main reasons why the respondents were unlikely to ride with AVs were lack of trust in the technology $(40 \%)$ and safety $(24 \%)$, while cost was only the third most relevant factor $(20 \%)$. A technology which is not perceived safe will not gain users. Safety itself can be looked at from several different angles. For example, Hulse et al. [21] point out that people's perception towards AVs depends on their road user perspective: AVs were perceived more dangerous as passengers and less dangerous as pedestrians. They add that this difference is possibly related to concerns about whose safety AVs will prioritize. A study by Dong et al. [2], focusing on autonomous public transportation concluded that the willingness of public transportation users to ride with an autonomous public transportation bus very much depends on the presence and tasks of the bus operator onboard. They point out that an onboard operator is especially crucial during the early stage of technology adoption, and there are also concerns that without the operator, certain groups such as disabled people will not receive assistance during the use of the service. It can be argued that such a concern points towards a general concern of safety onboard the bus.

One of the main worries with the previously mentioned studies is that the survey respondents have not been introduced with a real, physically existing technology. Although the study of Pakusch and Bossauer [19] was not introducing the autonomous technology to the participants, it was the only study focusing on the previous experience with fully autonomous transportation. As is argued by $\mathrm{Xu}$ et al. [22], participants in online surveys may not be able to visualize the operation and functionality of AVs. During the literature review, we found only seven studies that included actual vehicles with autonomous functionality. Six of these studies used automated shuttle buses without a steering wheel and pedals which offered first and last-mile public transportation service [23-30]. The study of Xu et al. used a rebuilt passenger car with steering wheel and pedals [22]. In most of these studies, the focus has been to determine user acceptability before and after having a direct experience with the technology. The study of Salonen and Haavisto [27] was based on the interviews conducted with people who just had used an AV. The study of Madigan et al. was based on the questionnaire which was filled by people who had at least once come across an operational AV, and the data was collected in the vicinity of two AV pilots (Lausanne and La Rochelle) [23]. Researchers from ETH Zürich have conducted multiple surveys as part of the Route 12 pilot in the Canton of Schaffhausen to investigate the public opinion towards the pilot [28-30]. One pre-pilot survey was followed by two follow-up surveys. The study of Harb et al. [11] is also worth mentioning. Although autonomous vehicles were not used, the researchers of that study provided chauffeurs to the participating households to simulate a privately-owned AV.

The study of Distler et al. [26] distinguishes acceptability and acceptance, of which the former refers to a prospective judgement before using the technology and the latter describes a person's judgement after using it. The study gives a clear example of how the judgement towards the technology can change after having a real experience with it. Participants of the Distler et al. [26] study significantly decreased their performance expectancy and perceived usefulness after having a chance to use an automated shuttle bus. The drop in perceived usefulness happened because the participants of the study had the first-hand experience with how limited the autonomy of these shuttles actually are. In the study by Xu et al. [22], trust, perceived usefulness and perceived ease of use increased among participants after they had first-hand experience with the technology. Nordhoff et al. [25] found that the participants of their study believed driverless shuttles to be useful and easy to use but not compared to their current travel modes. Perceived usefulness was also found as an important factor by Moták et al. [24]. Salonen and Haavisto [27] found that interviewees were acceptable towards AVs if they operate on a useful route. Similarly, the results of Madigan et al.'s study shows that the intention to use auto transportation is influenced by how well they believe it will perform in comparison with the existing public transportation options [23]. The surveys related to the Route 12 pilot in Switzerland show that the population's support towards automated shuttle bus pilots slightly increased after the start of the pilot, but it was statistically insignificant [28-30]. In the second survey, Wicki and Bernauer [30] also compared ride experience ratings between those participants of the general population survey who had taken a ride with the bus on Route 12 and the passengers who 
filled the survey right after the ride. The ride experience was slightly lower among the respondents of the general survey of whom $62.9 \%$ rated the experience with a grade " 4 " or " 5 " on a 5 -point scale (69.8\% among the passengers). Compared to the general survey participants, the passengers were also more eager to rate the experience with a grade " 5 " (41.7\% vs. $25.3 \%)$.

The studies of Distler et al. [26], Xu et al. [22], Salonen and Haavisto [27], and Wicki and Bernauer [28-30] have also investigated safety. The results of Xu et al.'s [22] study show that the participants whose perception of safety was high were more likely to use AVs in the future. In the study of Salonen and Haavisto [27], the participants expressed that the feeling of safety onboard the bus was better than they expected but people still had concerns regarding the overall safety of AVs in traffic. In the study of Distler et al. [26], the participants expressed that the actual experience with an automated shuttle bus had a reassuring effect on security and, in general, they felt safe in the bus. Their study also showed that both before and after riding with an AV, safety was one of the most important needs for the passengers. The results of the three Swiss surveys show that among the general population, the biggest concerns were related to software misuse [28-30]. Among the respondents of the second general survey who had taken a ride with the automated shuttle bus, over two-thirds of respondents rated safety as "good" or "very good" [30].

\subsection{Research Gap}

Our research adds to the previous discussions which have focused on automated shuttle buses in the context of first and last-mile public transportation service. The study identifies the differences in perception of safety and security between the passengers who recently experienced the technology and those who have not. Although the report of Wicki and Bernauer [29] compares the biggest concerns related to AVs throughout all three waves of surveys, they do not compare the perception of safety between people who have and have not taken a ride with an automated shuttle bus. The study of Salonen and Haavisto [27] does show that for many of the users, the experience with an automated shuttle bus enhances the feeling of safety. However, the study does not look at the exact difference before and after using the shuttle bus. The study of Distler et al. [26] shows that the importance of security as a basic human need did increase after the experience, although the participants expressed that the experience had a reassuring effect. Furthermore, it was also expressed that there were even too many security measures.

One can argue that the more safety precautions are implemented, the safer the passengers feel. In addition to comparing the perception of safety and security between the recent passengers and the control group that had not taken a ride with an AV bus, the current article also looks at the safety precautions as we link the perception of security and safety with how the pilot was set up. For that, we map out the main factors that can influence the everyday operations of automated shuttle buses and investigate how the issues were dealt with. This has not been done in the previous studies. However, we believe that the AV experience of the passengers can be influenced by factors such as the environment where the bus is driving or technical factors. For example, if the operation of the automated shuttle bus is interrupted by rain or some technical issue then it can negatively impact the experience compared to a situation where the bus is driving in perfect conditions.

\section{Case Study}

\subsection{Methods}

The main research method used in this paper is the case study method as we are focusing on one specific city with several tools for data collection applied (surveys, interviews, document analysis). Compared to other methods, the case study allows us to do in-depth analysis of one pilot site- the City of Tallinn. According to Yin [31], a case study investigates a contemporary phenomenon within its real-life context especially when the boundaries between phenomenon and context are not clearly evident. The case selection for this project is, on one hand, dependent on a potential to set up an 
open-street automated shuttle bus last-mile service pilot, and on the other hand, is dependent on a potential to gather primary data to study the link between user experience and automated mobility and various operational capacity factors influencing this. The collected data is both quantitative (especially survey questions on numeric scales) and qualitative (non-numeric responses in surveys, exclusively within a panel interview and log document analysis). Considering the theoretical framework and availability and access to primary data, the mixed methods approach is proposed that combines the following data:

- $\quad$ Passenger survey feedback analysis

- No-pilot control group survey feedback

- Daily communication log with shuttle operators

- Panel interview data of automated bus operators

\subsection{Passenger Safety and Security}

In the Sohjoa Baltic project, safety and security are reasoned in the following context [32]:

- "With autonomous driving still in its infancy, road safety is a topic followed closely by public, politics and researchers. When automated vehicles operate among others, and in normal traffic conditions, i.e., with other vehicles either autonomous or not, the probability of collisions and the impact of accidents is increased compared to operation in a closed environment. Due to differences in operating environments in between the pilot cities, variations in user experience is expected. The behavior of an automated vehicle can differ from a human driver, generating confusion and creating an uncomfortable or unsafe feeling about the ride, even if the accident rate does not increase or is even reduced. Passenger safety is understood here as the passengers' subjective feeling of traffic safety onboard an automated bus. The automated shuttle buses used in this study are designed in such a way that any traffic risk, triggered by sensor input, automatically results in sudden braking. Thus, the passengers' perception about safety can be altered by such hard braking, while also increasing the risk of falling for passengers standing in the bus or bumping into the interior parts of the bus. Road safety experience was surveyed by asking each passenger to respond with a grade from 1 to 7 about the safety onboard.

- Personal security on an autonomous vehicle is still largely an unknown factor. In our study, it is defined as the passengers' subjective feeling of security traveling with other passengers without the presence of a human driver, since the enclosed shared environment of an autonomous vehicle without a dedicated driver or supervisor might provide challenges to the personal security of the passengers. Experienced threats or perceived risks of safety both have a negative impact on the overall user experience and acceptance. Possible risks for personal security are, for instance, other passengers, people outside the vehicle, or cyber threats. The factors affecting the security were not surveyed. All the pilot projects were organized with a safety operator onboard, which may affect the perceived personal security. The topic was included in the survey nevertheless to provide a baseline for further pilots without a safety operator onboard, and to identify other possible issues related to security. The personal security was evaluated by respondents on a scale from 1 to $7 . "$

\subsection{Pilot Design}

The first long-term open traffic pilot in Tallinn, Estonia, with the SAE 3 level automated shuttle started its operations on 28 August 2019 around Kadriorg Park. The preparation process for this started already in October 2017 with the route selection. Three possible routes were found which could demonstrate a last-mile use case and had a low traffic intensity. Taking into consideration the possible changes in traffic arrangements that needed to be done, road conditions and the impact of the service, Kadriorg Park was selected as the best option. Later preparation activities included preparing changes in traffic arrangement on the selected route, public procurement process to rent an automated electric bus, and recruitment and training of shuttle-service operators. The rented bus is 
manufactured by the French company Navya and was delivered by the Danish company Holo who is the contract partner to the Tallinn Transport Department. According to the SAE International, this pilot was on SAE level "3-Conditional Driving Automation" where the driving task was fully automated with human fallback - operators had to respond promptly. The operators were students from Tallinn University of Technology who passed the two-week training organized by Holo. The operators were responsible for the safety of the bus and passengers as they took over control whenever it was necessary. The operators also explained to the passengers how the technology works. Other minor responsibilities included cleaning the bus, upgrading the software and sending data reports to the manufacturer. Before the start of operations, the bus had to pass an exam which was organized by the Estonian Road Administration to ensure the safety of the bus and its capability to drive in open traffic. In general, the bus was scheduled to run regularly from Tuesday to Sunday between 10.00-16.00 (till 18.00 on Thursday, Saturday and Sunday), and carried passengers free of charge. The bus seated up to eight passengers at a time with seatbelts fastened.

The bus served as a last-mile extension of the Kadriorg tram line connecting it with the Estonian Art Museum which is located $700 \mathrm{~m}$ away from the tram stop. The bus drove in a circle around the Kadriorg Park and had four stops: Katharinenthal cafeteria located close to the Kadriorg tram stop, Kadriorg Art Museum, Estonian Art Museum, and Miiamilla Children's Museum (Figure 1). In addition to several museums, the park is also a location for a small luna park and a tennis club. Several residential houses and a kindergarten are located at the Mäekalda street (south-west from the Estonian Art Museum). Most of the car traffic in the area is related to the Estonian Art Museum, residents who live at Mäekalda street, tennis club guests and people working in the Office of the President. Due to the pilot, traffic flow was changed on the Mäekalda and Koidula streets from two-way traffic to one-way traffic. The real-time position of the bus was available via the Letsholo app (available via Google Play or Apple App Store). Approximately 100 people were using the service during the operational days with 3877 users in total, although there were several issues that influenced the stability of operation resulting in a significant downtime in order to mitigate the risks. The operations were paused on 21.12.2019 due to seasonal conditions. Although the Tallinn pilot is planned to be reopened from 1.06 to 31.08.20 (Navya bus and some operators are ready for this during the time of writing this paper; provided COVID-19 restrictions will be over by June), key results can be drawn from the first operational period with a potential to update the survey results later.

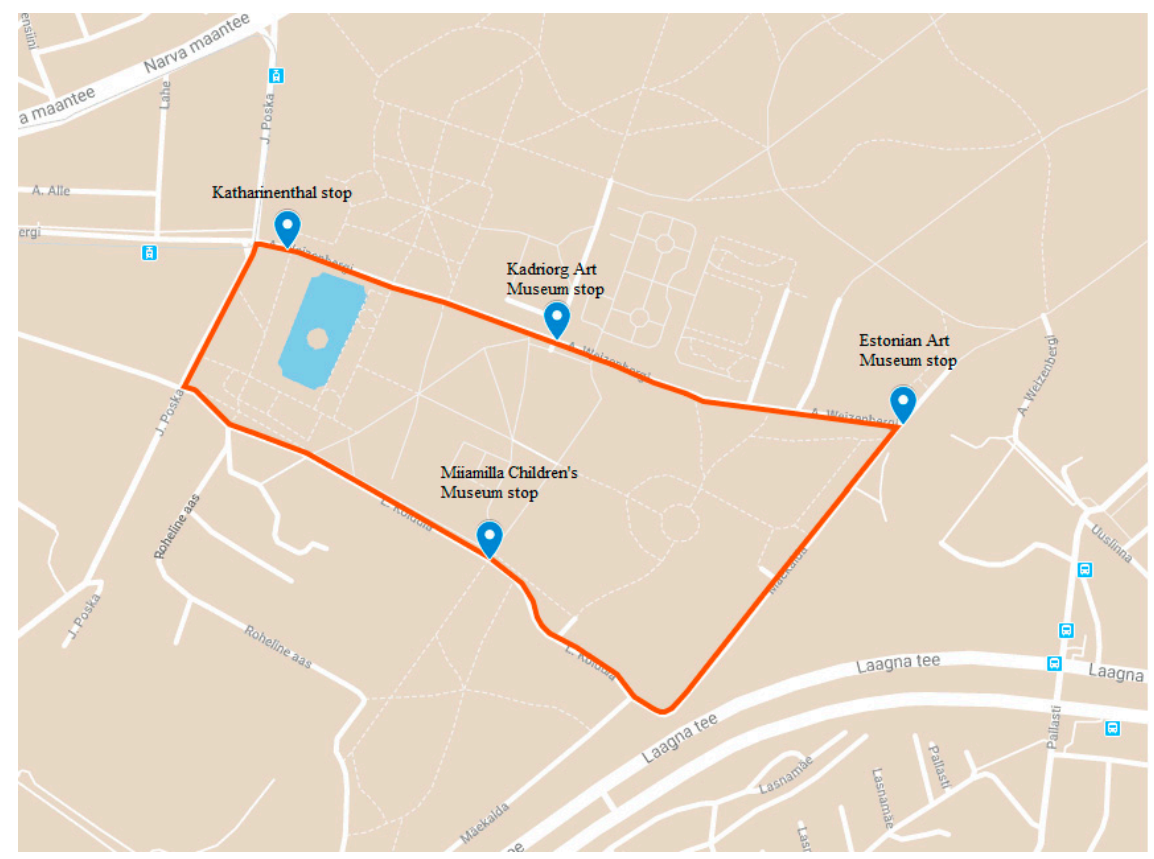

Figure 1. Route of the Tallinn automated shuttle pilot. 


\section{Key Characteristics:}

- $\quad$ Path length $(\mathrm{km}): 1.7 \mathrm{~km}$

- Average speed $(\mathrm{km} / \mathrm{h}): 7 \mathrm{~km} / \mathrm{h}$

- $\quad$ Travel time (min): 15

- Number of stops: 4

- Total number of users: 3877

\subsection{Perception Survey}

During the Tallinn pilot, passenger feedback was gathered via an anonymous online survey that was co-developed within the Sohjoa Baltic (www.sohjoabaltic.eu) project and used also in other pilot sites (in the European cities of Kongsberg, Helsinki and Gdansk). The aim was to provide a quick and easy to fill survey in order to increase the response rate. This is why only a number of questions were asked with limited depth. The survey form was designed in two parts: thematic questions regarding the general acceptance of the automated buses and demographic data about the passengers. The survey was run in two languages (Estonian and English).

This survey was available in Google Forms and distributed to participants via business card-size paper flyers (Figure 2) with an online link (taltech.ee/robotbus) and also a QR-code that directed the passengers to the survey in two languages. The survey invitations with general QR-codes were distributed exclusively to passengers after taking the ride. Technically, we cannot rule out the risk that some participants filled in the survey twice or distributed this invitation to non-participants. However, when comparing with other forms of collecting the same survey data (the city of Gdansk collected the same surveys on paper and the city of Helsinki asked participants to fill in the survey during the ride on a tablet), these results are similar-thus, there seems to be no systematic data entry error (see also www.sohjoabaltic.eu for comparative results which will be added by late Summer of 2020).

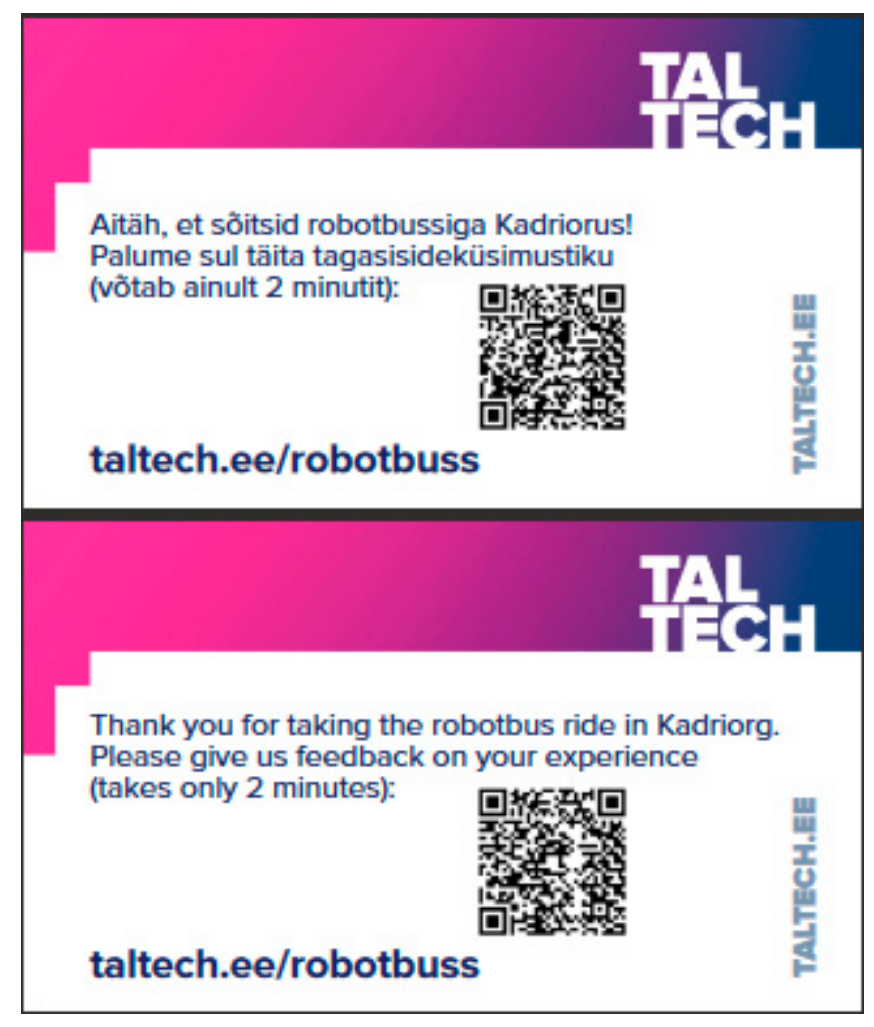

Figure 2. Feedback paper flyers distributed to passengers. 
The main analysis method of the survey was descriptive statistics, although a few correlation tests were also to be performed in order to analyze whether there are any statistically significant socio-demographic differences in the overall feedback to the experience. This survey does not represent the entire population as the sampling was not representing the passengers that voluntarily took the automated shuttle bus ride - this came from the pilot design with the goal to offer free and open service for everybody. There were no incentives for taking part in this survey.

The survey was designed within the Sohjoa Baltic project consortium, led by Metropolia University of Applied Sciences with the involvement of Chalmers University of Technology, Tallinn University of Technology (involving authors of this paper), mobility analytics company Flou and four Baltic Sea Region cities-Kongsberg (Norway), Gdansk (Poland), Tallinn (Estonia) and Helsinki (Finland). The goal was to design a simple fill-in survey that can be used across different pilot sites. The simplicity was an important factor to increase the take-up rates. The consortium first developed a board list of questions that were later ranked jointly against importance. During this period, guided by research and mobility experts, only the most important questions remained. In total, there were three rounds of joint workshops where the sequence, wording and scaling of questions were also discussed. For example, it was agreed to use the Likert scale with odd numbers for numeric questions (on the scale of 1-5 and 1-7 where 3 or 5 is neutral), as the consortium considered the safety and security more sensitive- - these were on the scale 1-7, whereas the overall experience was on the scale 1-5. Most questions allowed respondents to choose only one answer; only "When would you use this service?" allowed more than one answer. The main topics and questions were:

Traffic Safety: to study passengers' subjective feeling of safety (e.g., risk of accidents) in a real-life urban environment, after taking a ride with an automated bus. In general, compared to the previous 2017 pilot in Tallinn in a closed environment, the theoretical risk of collision is higher when this pilot is conducted in the open street environment (compared to no-traffic pilot). The survey question studying this link was: "How do you feel about general traffic safety onboard? Please mark on a scale of 1 (very unsafe) to 7 (very safe)."

Personal security: to study passengers' perceived feeling of security when the pilot is conducted in a real-life environment, after taking a ride with an automated bus. There was also a security risk related to the design of the robotbus as it is very sensitive to outside risks, received via sensors. Each potential outside risk triggers a sudden brake which can cause indoor accidents-this is the main reason why speed is capped. The survey question studying this link was: "How do you feel about your personal security onboard? Please mark on a scale of 1 (very unsafe) to 7 (very safe)."

Operator onboard: to study the willingness to participate in a pilot without operator onboard. In order to mitigate the risks, the bus always had an operator onboard who introduced the pilot's goals to the passengers and replied to various questions. In addition, the operator took over the control manually if it was needed. The survey question representing this interest was: "Would you also use the service with no operator onboard? Options: Yes, definitely; Yes, but not now; Maybe; No, never."

Automated last-mile use cases: to study the demand for automated last-mile shuttle service with predefined use cases. A multiple-choice survey question was: "When would you use this service? Options: In bad weather; When carrying heavy items; Daily commute; As a link to transport hubs/other Public Transport options; In closed large areas (e.g., campuses, industrial parks, airports, hospitals); Never; Other."

Safety for children: to study the perceived feeling of safety and security when the service is offered to vulnerable groups, e.g., school children. This question was designed as a potential control question to the perceived feeling of security and safety-all combined indicating trust towards automated mobility. The survey question was: "Would it be feasible for children to use this vehicle to travel to/from school? Options: Yes; Yes, but only if attended; No; Don't know."

Overall experience: to study the combined personal experience of the pilot. From the quantitative analysis perspective, this question was chosen to run various correlation tests between various socio-demographic groups as it represents the combined subjective experience. The survey question was: "How would you describe your experience? Please mark on a scale of 1 (very bad) to 5 (very good)." 
Frequency of use: to study the frequency demand for automated last-mile shuttle service. When the use case question above was mainly interested in the variety of demand for the last-mile service, this question was posed to study more narrow demand for the frequency of use. The survey question was: "If this service had been available as part of your daily commute, how often would you use it? Options: Daily; Weekly; Less often; Never."

General suggestion: to provide an option for passengers to give general feedback to the pilot, along with open questions regarding the future development expectations, both for planning next stage pilots and also for obtaining an indication in terms of perceived risks. The survey question was: "What wishes do you have about the future development on autonomous minibuses? Other feedback is also welcome!"

This was followed by socio-economic questions (sex, age, education, occupation, public transport usage).

Control group data was gathered during one smart city course among Tallinn University of Technology public administration bachelor-level students in late 2019 with a focus to study attitudes of Estonian students towards automated driving without actual driving experience. The service was introduced to the control group in the format of a lecture including introduction to the project goals and specific design of the route and pilot. Therefore, the questions were rephrased in order to investigate the perceived attitude towards automated driving in the control group. Students responded to this theoretical survey in December 2019 as part of their coursework. The results can be biased and do not represent the entire population as the survey was not voluntary nor fully anonymous. The following questions were asked:

- How would you feel about general traffic safety onboard?

- How would you feel about your personal security onboard?

- Would you also use the service with no operator onboard?

- When would you use this service?

- Would it be feasible for children to use this vehicle to travel to/from school?

- How would you (theoretically) describe your experience?

- If this service had been available as part of your daily commute, how often would you use it?

- What wishes do you have about the future development on autonomous minibuses? Other feedback is also welcome!

\subsection{Operators Issue Reporting and Panel Interview Data}

In order to analyze the risk mitigation via operational capacity of the pilot, operators' daily communication channel that covers the operational progress was analyzed. This channel was operational from late August to late December in the format of a Skype chat. In general, most operational challenges, issues and decisions went through this log, e.g., where and how to store the bus, how to provide maintenance and electricity, weekly update on the daily working shifts of the operators and various ad hoc issues ranging from leaves interrupting the automated mode to traffic accident descriptions and its technical consequences. This log file, when imported to a Word document, is approximately 215 pages and 47,000 words.

In order to perform document analysis, a qualitative research software based on text-coding and analysis was applied using the ATLAS.ti software in order to map the operational capacity factors of automated vehicles in three dimensions. The purpose of ATLAS.ti qualitative data analysis software is to systematically analyze complex phenomena hidden in unstructured data (text, multimedia, geospatial). The program provides tools that let the user locate, code, and annotate findings in primary data material, to weigh and evaluate their importance, and to visualize the often-complex relations between them. ATLAS.ti consolidates large volumes of documents and keeps track of notes, annotations, codes and memos that require close study and analysis of primary material consisting of 
text, images, audio, video, and geo data. In addition, it provides analytical and visualization tools designed to open new interpretative views on the material.

We came up with code words to find out main issues related to technology, traffic and environment and their frequency. The code words were based on the area where the bus was driving (park), technical aspects of the bus and the discussions in the Skype chat. Table 1 illustrates the used code words under each topic and their frequency. The frequency of the code words gives only a partial overview of the main issues. For example, the words "Signal" and "GPS/GNSS" have a low frequency, the fact that there were issues with GNSS signal paused the operations for several weeks (see Section 4.3).

Table 1. The coding strategy of the log file.

\begin{tabular}{cc}
\hline Topic & Used Code Words (Frequency) \\
\hline Technical & Technical, Signal (3), GPS/GNSS (3), Mechanical (1), Battery (45), Computer (4), \\
Software (5), Door/s (79), Tire/s (8), Wheel/s (2) \\
$\begin{array}{c}\text { Traffic } \\
\text { Environment }\end{array}$ & Car (48), Parking (30), Congestion (2), Pedestrian, People/Person (96), Sign (8), \\
Bicycle (1)
\end{tabular}

In addition to the document analysis, we invited all four operators to a face-to-face panel interview that took place in the beginning of February 2020. The panel interview with joint discussions and responses from operators took approximately $1.5 \mathrm{~h}$ and it was recorded. The aim of the panel interview was to gather additional feedback from operators that participated in all rides, regarding the technology, traffic and environmental operational capacity factors. The openly structured questions were the following, translated from Estonian:

- Please describe your operational experience on the Navya shuttle bus and its technology (sensors, software etc.)

- How long did you operate issue-free?

- What were the most common issues during the operation?

- What caused these issues (environment, technology, traffic)?

- What were the main weather conditions that influenced the operation? (Specific questions on the impact of precipitation, wind, temperature, extreme weather condition etc.)

- How many issues directly or indirectly influenced the weather? (on the scale from 1-10)?

- Could you describe the split between routine and dynamic factors?

\section{Results}

In total, 152 passengers answered the survey out of the 3877 people that took the ride between late August to late December with a response rate of $4 \% .55 .3 \%$ of the respondents were women and $44.7 \%$ were men. $35.5 \%$ of the respondents were between the ages of 31-45, making it the most dominant age group. The least represented group was $>61$ as only $10.5 \%$ of the respondents were part of this age group. A large majority, $62.5 \%$ of respondents, reported that they were employed. $14.5 \%$ of respondents were students, $12.5 \%$ self-employed or other, and $9.9 \%$ were retired or unemployed. The survey was dominated by people with higher education as $64.5 \%$ reported that they had a university degree. $20.4 \%$ of respondents had a secondary education or vocational degree (see Figure 3 ). 
(a)

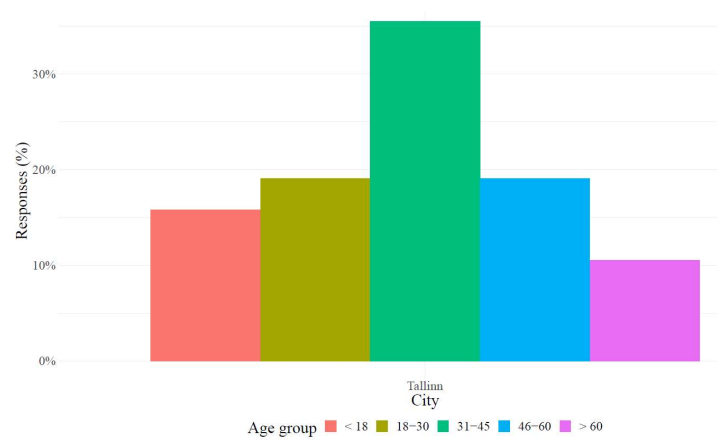

(c)

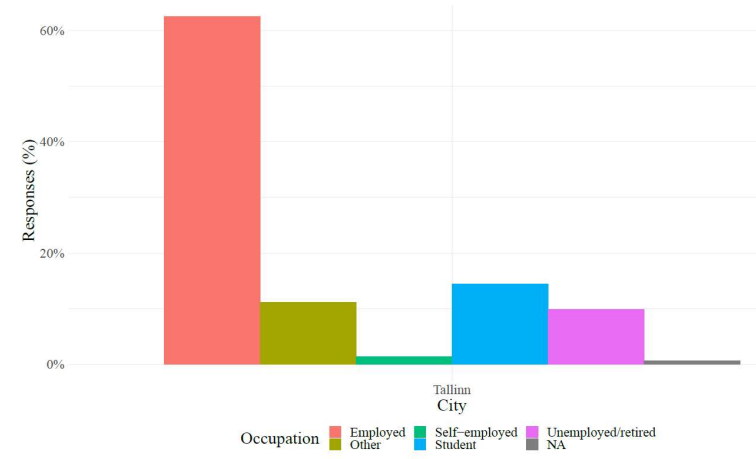

(b)

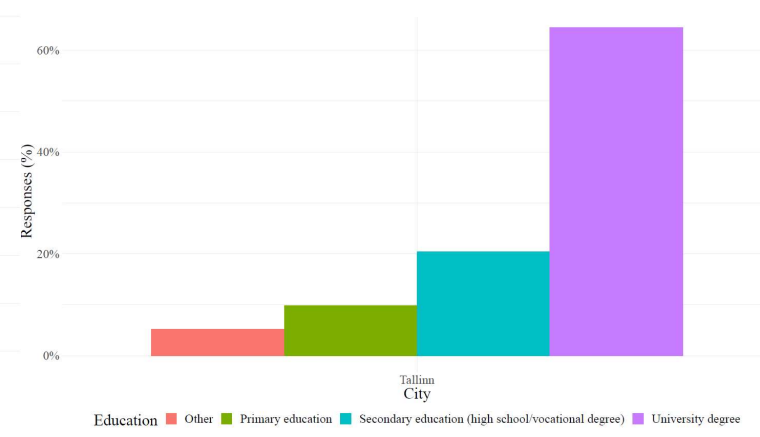

(d)

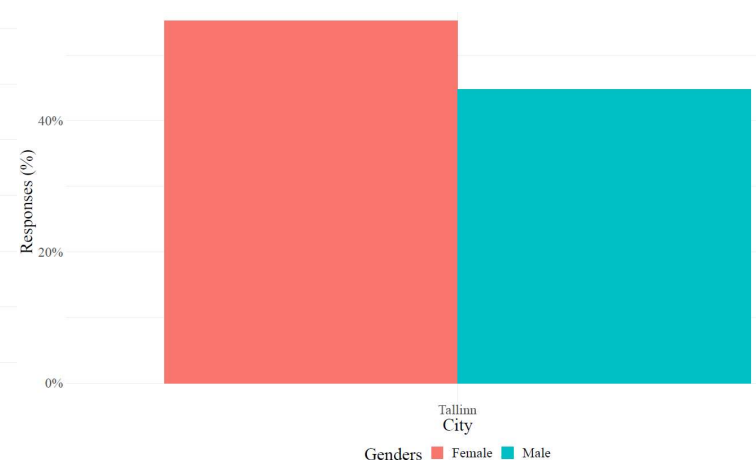

Figure 3. Socio-economic data of respondents: age (a); education (b); occupation (c) and gender (d).

\subsection{Automated Driving Experience and Implemented Safety and Security Precautions}

When operated, the risks were reduced by always having an operator onboard and also by careful design of a pilot including low-intensity traffic and mandatory seatbelts. Specifically, the mobility risks were mitigated by relatively low average speed $(7 \mathrm{~km} / \mathrm{h})$ with maximum speed capped at around $15 \mathrm{~km} / \mathrm{h}$ for a $1700 \mathrm{~m}$ route with four stops (average time was $15 \mathrm{~min}$ for a full ride). The pilot ran in low-intensity traffic with no traffic lights, with relatively simple junctions, and avoided service during the weekly peak times (the service was not operated during the weekdays between 8:00-10:00 and 16:00-18:00). Most importantly, an operator was always ready to take over the manual control.

The importance of safety precautions also came out in the panel interview with operators that indicated a rather high amount of downtime. For example, during three weeks in October, approximately $50 \%$ of the time, the service was not operational in order to prioritize the safety and security of passengers (see also Figure 4).

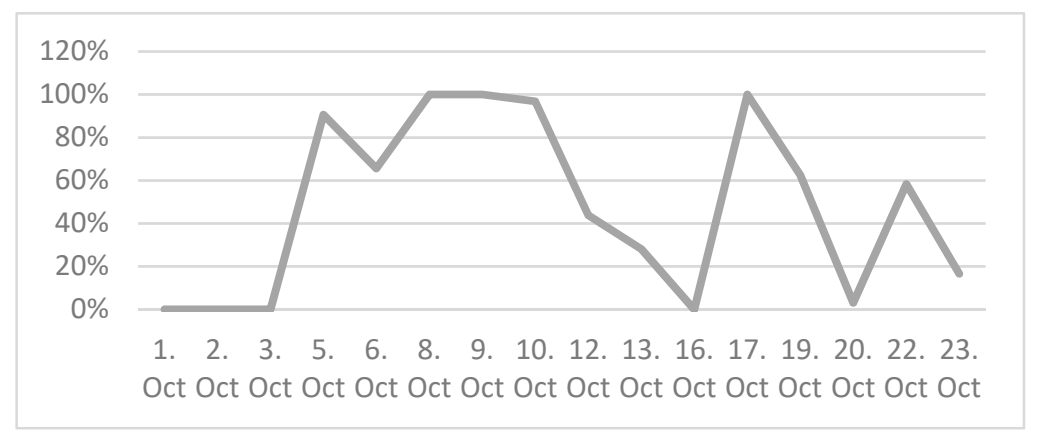

Figure 4. Actual versus planned hours in operation. 
In this mitigated risk situation, the general feedback from 152 passengers taking the ride was remarkably positive with no extremely negative scores, see Table 2 . In order to analyze potential socio-economic factors influencing the overall feedback, we also performed a regression analysis based on generalized linear regression coefficients, see Table 3. As a result, none of the variables have statistically significant effect on the overall experience score, making correlation analysis not central to this study.

Table 2. Mean scores on safety, security and overall experience.

\begin{tabular}{cccc}
\hline & Mean & Median & Scale \\
\hline Traffic safety & 6.06 & 6 & 1 (very unsafe) to 7 (very safe) \\
Personal security & 6.33 & 7 & 1 (very unsafe) to 7 (very safe) \\
Overall experience & 4.79 & 5 & 1 (very bad) to 5 (very good) \\
\hline
\end{tabular}

Table 3. Regression analysis.

\begin{tabular}{|c|c|c|c|c|c|}
\hline \multicolumn{2}{|c|}{ Factor } & \multirow{2}{*}{$\begin{array}{c}\text { Estimate } \\
4.84\end{array}$} & \multirow{2}{*}{$\begin{array}{c}\text { Std. Error } \\
0.27\end{array}$} & \multirow{2}{*}{$\begin{array}{c}t \text { Value } \\
17.72\end{array}$} & \multirow{2}{*}{$\frac{\operatorname{Pr}(>|t|)}{0}$} \\
\hline & Intercept & & & & \\
\hline \multirow{3}{*}{ Education } & Primary education & -0.13 & 0.24 & -0.53 & 0.6 \\
\hline & Secondary education & 0.19 & 0.25 & 0.76 & 0.45 \\
\hline & University degree & -0.04 & 0.25 & -0.15 & 0.88 \\
\hline \multirow{4}{*}{ Age } & $>60$ & -0.12 & 0.33 & -0.35 & 0.72 \\
\hline & $18-30$ & -0.01 & 0.26 & -0.03 & 0.98 \\
\hline & $31-45$ & -0.16 & 0.28 & -0.6 & 0.55 \\
\hline & $46-60$ & -0.05 & 0.28 & -0.19 & 0.85 \\
\hline Gender & Male & 0 & 0.09 & -0.01 & 0.99 \\
\hline \multirow{4}{*}{ Occupation } & Other & 0.04 & 0.21 & 0.19 & 0.85 \\
\hline & Self-employed & 0.07 & 0.41 & 0.17 & 0.86 \\
\hline & Student & 0.13 & 0.17 & 0.74 & 0.46 \\
\hline & Unemployed/retired & 0.14 & 0.2 & 0.73 & 0.47 \\
\hline \multirow{3}{*}{$\begin{array}{l}\text { How often public } \\
\text { transit used }\end{array}$} & Less often & 0.06 & 0.11 & 0.56 & 0.58 \\
\hline & Never & 0.18 & 0.34 & 0.53 & 0.59 \\
\hline & Weekly & -0.11 & 0.11 & -1.04 & 0.3 \\
\hline
\end{tabular}

Carefully managed risks also indicated that people are more willing to use the minibus without an operator onboard, either already now or in the future (most people responded "yes, definitely" or "yes, but not now" to the question "Would you use it without an operator onboard?"). This also is represented in the question regarding feasibility for the use of kids-the vast majority of respondents would allow children to use the service to travel to/from school, either alone or attended (Figure 5).

There were no clear differences regarding the preferred use cases of the automated shuttle service-demand for last-mile, bad weather, heavy items and closed areas was relatively equally represented, with no-use case option ("never") not selected. On the other hand, respondents would prefer to use this service for the daily or weekly commute-indicating actual need for the last-mile service between the tram stop and the National Art Museum (most responses, see Figure 6). 
(a)

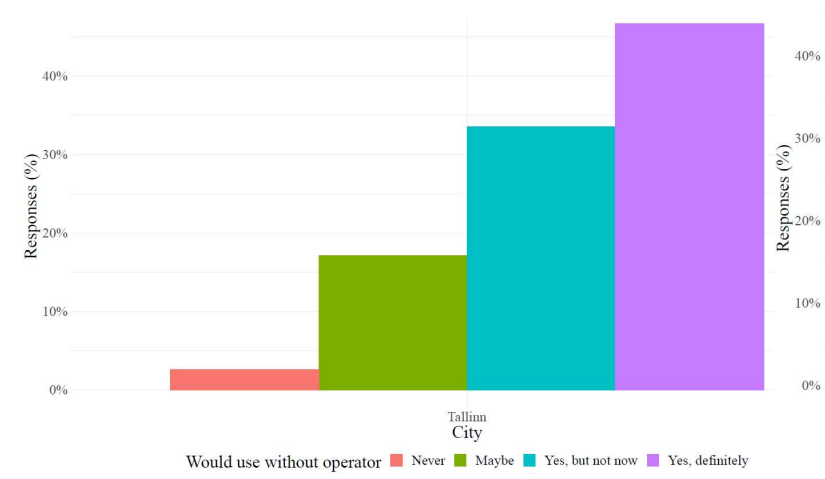

(b)

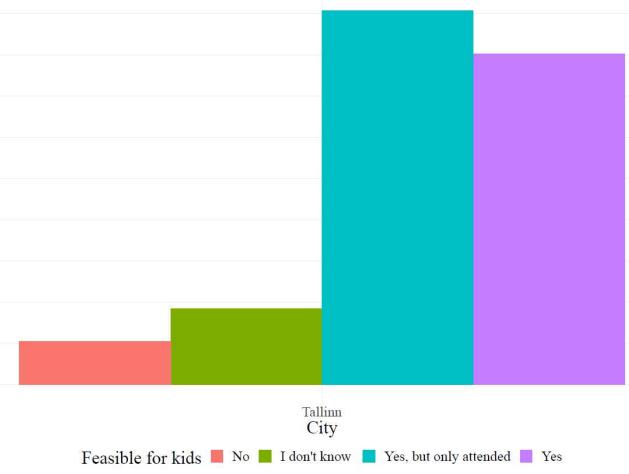

Figure 5. Use without operator (a) and feasibility for children (b).

(a)

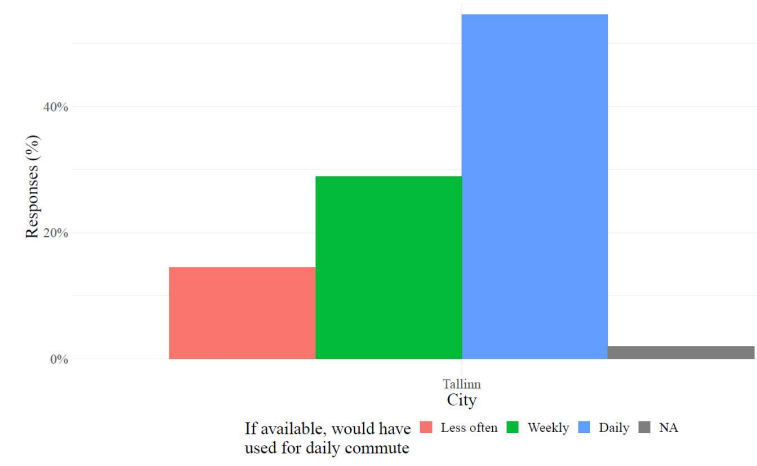

(b)

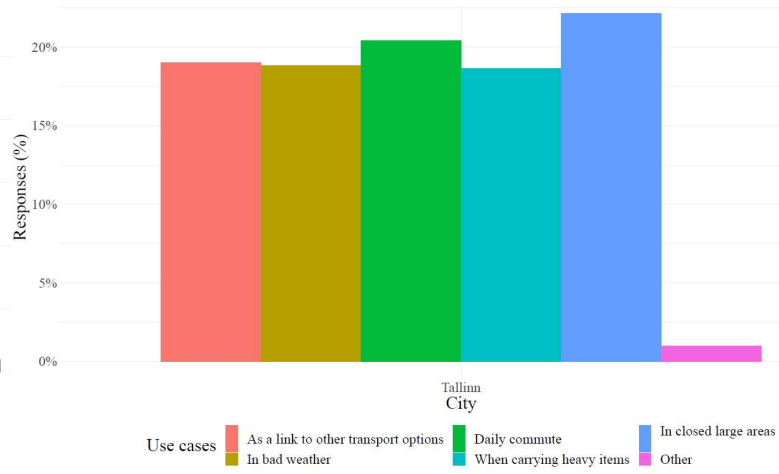

Figure 6. Demand for the automated bus service: commuting frequency (a) and preferred use cases (b).

\subsection{Automated Driving User Experience in Terms of Safety and Security}

Passengers taking the ride gave strong positive feedback to the general safety and security onboard questions, see also Table 2. On the other hand, when asked the same questions from the control group (55 respondents) in a more theoretical way, without being linked to the actual driving experience ("How would you feel about general traffic safety onboard?" and "How would you feel about your personal security onboard?"), this gave significantly lower average scores (4.8 and 5.0, respectively). Thus, we can conclude that the group that took the ride perceived safety and security significantly differently compared to the group with no driving experience (see Table 4). However, these differences cannot be claimed to be statistically significantly different as they represent different populations. In the group taking the ride, most people were employed, had university education and were most often in the age group of 31-45-see also Figure 3 above. This survey was done in two languages-Estonian (87 responses) and English (65 responses) and was both fully voluntary and anonymous. However, the "no pilot" group consisted of Estonian students of whom over $90 \%$ were females in the age group of 18-30. The survey was also not fully anonymous nor voluntary.

Table 4. Mean scores on safety and security (pilot/control group).

\begin{tabular}{cccc}
\hline & Pilot Group & Control Group & Scale \\
\hline Traffic safety & 6.06 & 4.82 & 1 (very unsafe) to 7 (very safe) \\
Personal security & 6.33 & 5.07 & 1 (very unsafe) to 7 (very safe) \\
Number of respondents & 152 & 55 & \\
\hline
\end{tabular}




\subsection{Key Factors Influencing the Daily Operations of an Automated Shuttle Bus}

Based on the panel interview and the daily communication channel analysis, we can say that the most common issues that hindered the bus operation were related to traffic and environment or were technical in nature. Due to that, the automated shuttle bus had significantly more issues with downtime than expected, as explained earlier.

Firstly, several technical issues were experienced during the pilot. The biggest technical issue was related to GPS connection, which, for some time, made it impossible to operate the bus autonomously. There was also a mechanical issue with doors which prevented them to open and close properly. Although the error was not related to sensors, cameras or the GPS which help to make the vehicle autonomous-according to the operators, this decreased passengers' trust towards the technology as it was a visible error. There were also problems with charging the battery as the museum's electric panel often switched off due to overload. Additionally, the air conditioning did not work properly which made it more complicated to work in low temperatures in November and December. The main reason for several technology-related errors was that the technical support was provided from a distance (from Denmark and/or France). For example, there was an issue with doors not working properly and it took one operator four days to understand how to open and close these doors. In addition, the distant problem-detection decision tree assumed that most challenges are related to issues with software, although the problem with doors was actually a mechanical one.

Secondly, traffic also influenced the operational capacity. Despite low-intensity traffic, several traffic-related issues were brought up by bus operators. For example, the bus did not understand that it is in a traffic jam and started to "beep" as it thought there was an obstacle in front. In addition, everyday operations were influenced by cars parked on the road (often not legally) and cars driving against the rules in the opposite direction on a one-way street. As the bus was operational around one popular park, there were also issues with pedestrians who either crossed the road in the wrong place or, on purpose, tested whether the bus would stop or not, if suddenly interacted with. The operation was ceased for weeks due to one traffic accident with a heavy goods vehicle which ignored the automated bus and hit it at a slow speed.

Lastly, several environmental factors affected the operations. According to operators, weather had a significant impact on the operation. During the operations from the end of August till December 21st, the main issues linked to weather conditions were related to rain, leaves, and temperature. All these issues also occurred due to seasonal changes. Rain, falling and already fallen leaves were the main weather-related issues in September and October. While falling and already fallen leaves caused the bus to have an emergency stop 10-15 times per circle, the combination of leaves with heavy rain made it impossible for the bus to drive smoothly. During such times, the operation was paused and continued when the rain stopped. In December, temperature started to become an issue because of two reasons. When the bus was not operating, it was stored in the outside tent located at the parking lot of the Estonian Art Museum as there was no warm garage in the vicinity that could be used. After each day of operation, the bus was left in the tent with its battery charging for the next morning. As battery charging needed at least more than 5 degrees Celsius temperature, the tent was equipped with additional radiators to keep the temperature above that threshold. Extreme temperatures made it also necessary to turn on the heating or air conditioning which decreased the daily operating hours because of the increased power consumption. In addition to the weather, other environmental factors played a role. For example, the bus stopped due to birds that flew in front of the sensors as the bus recognized them as obstacles. The bus also stopped due to outgrown tree branches, especially during the heavy wind. The biggest environmental issue was the seasonal change. After the leaves completely fell from the trees, the bus did not recognize the environment as it did not match with the pre-mapped route and the pilot had to be paused till the Navya technicians solved the problem. 


\subsection{Open Feedback and Suggestions for Future Pilots}

In the case of the open feedback questions of the pilot survey, positive comments dominated. In total, 61 people gave additional comments (frequency of $40 \%$ ). Most of the suggestions and comments dealt with the size of the bus, smoothness of the ride, capability of the bus to overcome obstacles, the wish for more pilots, and feedback about bus operators. Several people pointed out that the bus is too small. This refers to the fact that the bus was operational in one of the main parks in Tallinn which is also a popular tourist destination. In crowded areas like Kadriorg Park, it would be reasonable to provide the last-mile service with at least two buses. Survey respondents also wished for more such pilots in areas where last-mile service would be needed and for popularization reasons. Survey respondents also wished that the bus could better detect and pass obstacles, evaluate the surrounding environment, drive more smoothly and without bumpy breaks which can happen due to unexpected obstacles, and read traffic signs. These issues are mostly related to the technological limitations. It might also refer to the fact that people have high expectations towards the technology and expect close to zero errors. People also pointed towards the issues with connectivity which happened during the pilot as the bus used GNSS as one of the tools for navigation. Several positive comments were left about the bus operators. Respondents were happy to get additional bus-related information from the operators. One respondent pointed out that an operator was very useful while the bus had technical issues. It shows that during the early piloting and adoption of the technology, bus operators are important. Another respondent wished for this bus to have similar speed to manually driven buses.

\section{Discussion and Conclusions}

The current paper is an addition to the research which investigates mobility acceptance towards AVs. The key contribution of this paper is to point out that it is not so much perceived safety and security concerns but rather technological challenges of integrating such a last-mile service with urban mobility. Compared to most other studies that are based on online surveys and give no possibility for respondents to actually experience the technology, the current study investigates user acceptance after they had taken a ride with an automated shuttle bus. A total of 152 people out of 3877 passengers answered the survey. Passengers taking the ride with an automated minibus provided positive feedback on security and safety and overall experience. In the regression analysis of the overall feedback and socio-demographic factors, we did not find any statistically significant differences-this could be due to the biased data towards good experience grades. To ensure traffic and passenger safety, the bus did not offer service for passengers if major issues or risks were identified. This resulted in significant downtime of the service. Thus, we can say that the service was offered only during close to perfect conditions.

The results were compared with a control group that consisted of 55 students who did not take a ride with the shuttle. Passengers taking the ride gave more positive feedback to the general safety and security onboard questions compared to the control group. These results are also in line with several other studies that have shown that the ride with an automated shuttle bus had a reassuring effect on safety [26] or that the experience enhances the feeling of safety [27]. Based on these results, we can argue that the feedback from passengers to an automated driving experience is also related to the risk management during the pilots as the bus was operational only when the conditions were close to perfect and allowed a smooth drive.

We can say that the most common issues that hindered the bus operation were related to traffic and environment or were technical in nature, thus making this dimension important for future mobility risk management. Importantly, the technical issues were considered as the biggest ones. The issues were related to the technology that makes the shuttle autonomous but were also more trivial such as issues with doors. Although it is understandable that the development of sensors, radars and other technologies, which makes a vehicle autonomous, is the priority for these companies, cutting corners from mechanical reliability can have negative implications from the user acceptability side. 
The study has several limitations related to how the pilot was conducted and how the survey was designed. This survey does not represent the entire population as the sampling was not representing the passengers that voluntarily took the automated shuttle bus ride- this came from the pilot design with a goal to offer free and open service for everybody. For future research, an interesting contribution would be to invite participants based on sampling tools-only the ones invited from the general population could participate in the survey. In addition, the control group could be also sampled from the same pool. To our knowledge, this kind of randomized approach is lacking in the literature. The survey could benefit from a higher response rate, e.g., by having a paper-based alternative. Paper-based responses could increase the response rate among elderly people who, in the current survey, were an underrepresented group. Although the bus was driving in open traffic, the pilot was carried out in the area which has a much lower traffic intensity compared to most other parts of the city. The speed was also limited to $15 \mathrm{~km} / \mathrm{h}$. It is also important to point out that for safety precautions, the operation was paused if during severe rain, the bus started to make emergency brakes. These factors could have improved the feeling of safety among the passengers. One of the main limitations of the survey was the fact that the respondents were not chosen based on a random sample. All respondents were passengers who chose to respond to the survey themselves. This limits the generalization of the results to a wider population. For example, the majority of respondents were people with higher education. We can assume that these people are also keener towards using and testing new technologies compared to the rest of the population. Although, according to the operators, the bus mostly served elderly people, they were underrepresented in the survey. The reason for this was probably the fact that the survey took place online. The survey also did not provide much in-depth information about respondents' mobility patterns or socio-economic or health status.

For further research, focus should be directed towards socio-economic groups that so far have been underrepresented in different studies. These include people with different disabilities, elderly people or children. Such research would provide valuable insight about the needs that every such group has in using autonomous technology. For example, people with different disabilities might feel more uncomfortable if there is no driver/operator in the vehicle, as they might need help in using transportation. Therefore, the question for AV manufacturers, public transport authorities and operators is which obstacles can be solved and how they can be solved.

Author Contributions: The first author (R.-M.S.) as has been responsible for the research design and publication strategy throughout the process. The second author (J.M.) has significantly contributed to the overall scientific quality of the paper. In addition, a few S.B. team members have contributed to this paper with smaller roles (e.g., regression analysis and illustrations were partially performed by T.K. and S.M. from Flou; Section 3.2 process was led by M.B. from Chalmers University). All authors have read and agreed to the published version of the manuscript.

Funding: This research was funded by the EU-Interreg through the Sohjoa Baltic project, grant number R073. The FinEst Smart City Center of Excellence part was additionally supported by the H2020 project "Finest Twins," grant number 856602 .

Conflicts of Interest: The authors declare no conflict of interest.

\section{References}

1. Bansal, P.; Kockelman, K.M. Are we ready to embrace connected and self-driving vehicles? A case study of Texans. Transportation 2018, 45, 641-675. [CrossRef]

2. Dong, X.; DiScenna, M.; Guerra, E. Transit user perceptions of driverless buses. Transportation 2019, 46, 35-50. [CrossRef]

3. Haboucha, C.J.; Ishaq, R.; Shiftan, Y. User preferences regarding autonomous vehicles. Transp. Res. Part C 2017, 78, 37-49. [CrossRef]

4. Kyriakidis, M.; Happee, R.; de Winter, J.C.F. Public opinion on automated driving: Results of an international questionnaire among 5000 respondents. Transp. Res. Part F Psychol. Behav. 2015, 32, 127-140. [CrossRef]

5. Zmud, J.; Sener, I.N.; Wagner, J. Self-Driving Vehicles: Determinants of Adoption and Conditions of Usage. Transp. Res. Rec. J. Transp. Res. Board 2016, 2565, 57-64. [CrossRef] 
6. Fagnant, D.J.; Kockelman, K.M. The travel and environmental implications of shared autonomous vehicles, using agent-based model scenarios. Transp. Res. Part C Emerg. Technol. 2014, 40, 1-13. [CrossRef]

7. Fagnant, D.J.; Kockelman, K.M. Dynamic ride-sharing and fleet sizing for a system of shared autonomous vehicles in Austin, Texas. Transportation 2018, 45, 143-158. [CrossRef]

8. OECD. Urban Mobility System Upgrade: How shared self-driving cars could change city traffic. Corp. Partnersh. Board Rep. 2015, 96, 776-778. [CrossRef]

9. Martinez, L.M.; Viegas, J.M. Assessing the impacts of deploying a shared self-driving urban mobility system: An agent-based model applied to the city of Lisbon, Portugal. Int. J. Transp. Sci. Technol. 2017, 6, 13-27. [CrossRef]

10. Meyer, J.; Becker, H.; Bösch, P.M.; Axhausen, K.W. Autonomous vehicles: The next jump in accessibilities? Res. Transp. Econ. 2017, 62, 80-91. [CrossRef]

11. Harb, M.; Xiao, Y.; Circella, G.; Mokhtarian, P.L. Projecting travelers into a world of self-driving vehicles: Estimating travel behavior implications via a naturalistic experiment. Transportation 2018, 45, 1671-1685. [CrossRef]

12. Kim, K.; Yook, D.; Ko, Y.; Kim, D. An Analysis of Expected Effects of the Autonomous Vehicles on Transport and Land Use in Korea. Work. Pap. 2015, 1-29. Available online: http://marroninstitute.nyu.edu/uploads/ content/Kim,YYookDevelopment_of_Autonomous_Driving_SystemMarron.pdf (accessed on 6 July 2020).

13. Fassbender, D.; Heinrich, B.C.; Wuensche, H.J. Motion planning for autonomous vehicles in highly constrained urban environments. In Proceedings of the 2016 IEEE/RSJ International Conference on Intelligent Robots and Systems (IROS), Daejeon, Korea, 9-14 October 2016; pp. 4708-4713. [CrossRef]

14. Zhang, W.; Guhathakurta, S. Parking spaces in the age of shared autonomous vehicles: How much parking will we need and where? Transp. Res. Rec. 2017, 2651, 80-91. [CrossRef]

15. Clements, L.M.; Kockelman, K.M. Economic Effects of Automated Vehicles. Transp. Res. Rec. J. Transp. Res. Board 2017, 2606, 106-114. [CrossRef]

16. Ainsalu, J.; Arffman, V.; Bellone, M.; Ellner, M.; Haapamäki, T.; Haavisto, N.; Josefson, E.; Ismailogullari, A.; Lee, B.; Madland, O.; et al. State of the art of automated buses. Sustainability 2018, 10, 3118. [CrossRef]

17. Ongel, A.; Loewer, E.; Roemer, F.; Sethuraman, G.; Chang, F.; Lienkamp, M. Economic assessment of autonomous electric microtransit vehicles. Sustainability 2019, 11, 648. [CrossRef]

18. Cohen, S.A.; Hopkins, D. Autonomous vehicles and the future of urban tourism. Ann. Tour. Res. 2019, 74, 33-42. [CrossRef]

19. Pakusch, C.; Bossauer, P. User Acceptance of Fully Autonomous Public Transport. In Proceedings of the 14th International Joint Conference on e-Business and Telecommunications (ICETE 2017), Madrid, Spain, 24-26 July 2017; Volume 2, pp. 52-60. [CrossRef]

20. Fagnant, D.J.; Kockelman, K. Preparing a nation for autonomous vehicles: opportunities, barriers and policy recommendations. Transp. Res. Part A 2015, 77, 167-181. [CrossRef]

21. Hulse, L.M.; Xie, H.; Galea, E.R. Perceptions of autonomous vehicles: Relationships with road users, risk, gender and age. Saf. Sci. 2018, 102, 1-13. [CrossRef]

22. Xu, Z.; Zhang, K.; Min, H.; Wang, Z.; Zhao, X.; Liu, P. What drives people to accept automated vehicles? Findings from a field experiment. Transp. Res. Part C Emerg. Technol. 2018, 95, 320-334. [CrossRef]

23. Madigan, R.; Louw, T.; Dziennus, M.; Graindorge, T.; Ortega, E.; Graindorge, M.; Merat, N. Acceptance of Automated Road Transport Systems (ARTS): An Adaptation of the UTAUT Model. Transp. Res. Procedia 2016, 14, 2217-2226. [CrossRef]

24. Moták, L.; Neuville, E.; Chambres, P.; Marmoiton, F.; Monéger, F.; Coutarel, F.; Izaute, M. Les variables prédictives des intentions d'utilisation d'une navette autonome: Aller au-delà du MAT et de la TCP ? Rev. Eur. Psychol. Appl. 2017, 67, 269-278. [CrossRef]

25. Nordhoff, S.; van Arem, B.; Merat, N.; Madigan, R.; Ruhrort, L.; Knie, A.; Happee, R. User Acceptance of Driverless Shuttles Running in an Open and Mixed Traffic Environment. In Proceedings of the 12th ITS European Congress, Strasbourg, France, 19-22 June 2017; pp. 1-14. [CrossRef]

26. Distler, V.; Lallemand, C.; Bellet, T. Acceptability and acceptance of autonomous mobility on demand: The impact of an immersive experience. In Proceedings of the $2018 \mathrm{CHI}$ Conference on Human Factors in Computing Systems, Montreal, QC, Canada, 21-26 April 2018; pp. 1-10. [CrossRef]

27. Salonen, A.O.; Haavisto, N. Towards autonomous transportation. Passengers' experiences, perceptions and feelings in a driverless shuttle bus in Finland. Sustainability 2019, 11, 588. [CrossRef] 
28. Wicki, M.; Bernauer, T. Public Opinion on Route 12, Interim report on the first survey on the pilot experiment of an automated bus service in Neuhausen am Rheinfall, ISTP Paper Series, 3, Institute of Science, Technology and Policy (ISTP), ETH Zürich, Zürich. 2018.

29. Wicki, M.; Bernauer, T. Public Opinion on Route 12, Interim report on the second survey on the pilot experiment of an automated bus service in Neuhausen am Rheinfall, ISTP Paper Series, 4, Institute of Science, Technology and Policy (ISTP), ETH Zürich, Zürich. 2019.

30. Wicki, M.; Bernauer, T. Public Opinion on Route 12, ISTP Paper Series, 5, Institute of Science, Technology and Policy (ISTP), ETH Zürich, Zürich. 2020. [CrossRef]

31. Yin, R. The Case Study Crisis: Some Answers. Adm. Sci. Q. 1981, 26, 58. Available online: http: //www.jstor.org/stable/10.2307/2392599 (accessed on 25 May 2013). [CrossRef]

32. Bellone, M.; Ismailogullari, A.; Kantala, T.; Mäinen, S.; Soe, R.-M.; Åman Kyyröe, M. A Cross-Country Comparison of User Experience of Public Autonomous Transport. Submitted to the European Transport Research Review [Under Review].

(C) 2020 by the authors. Licensee MDPI, Basel, Switzerland. This article is an open access article distributed under the terms and conditions of the Creative Commons Attribution (CC BY) license (http://creativecommons.org/licenses/by/4.0/). 